and Polish Ministry of Science and Higher Education (core grant S/17).

Disclosure of interest None declared

\section{P055 INTERLEUKIN-7 IN AORTIC ADVENTITIA OF PATIENTS WITH RHEUMATOID ARTHRITIS AND CORONARY ARTERY DISEASE}

\begin{abstract}
${ }^{1}$ AN Burska* ${ }^{2} \mathrm{~K}$ Sime, ${ }^{2} \mathrm{~A}$ Williams, ${ }^{3} \mathrm{~K}$ Mikkelsen, ${ }^{4} \mathrm{~K}$ Saatvedt, ${ }^{5} \mathrm{SM}$ Almdahl, ${ }^{6}$ I Risnes, ${ }^{6}$ SE Rynning, ${ }^{7} \mathrm{C}$ Goodyear, ${ }^{8,9} 1$ Hollan, ${ }^{1} \mathrm{~F}$ Ponchel. 'Leeds Institute of Rheumatic and Musculoskeletal Medicine, University of Leeds, Leeds; ${ }^{2}$ Division of Infection and immunity, Cardiff University School of Medicine, Cardiff, UK; ${ }^{3}$ Lillehammer Hospital for Rheumatic Diseases, Lillehamer; ${ }^{4}$ Department of cardiothoracic surgery, Oslo University Hospital, Oslo; ${ }^{5}$ Department of cardiothoracic surgery, University Hospital of North-Norway, Tromse; ${ }^{6}$ Department of cardiothoracic surgery, Feiring Heart Clinic, Feiring, Norway; ${ }^{7}$ Institute of Infection, Immunity and inflammation, University of Glasgow, Glasgow, UK; ${ }^{8}$ Department of Medicine, Brigham and Women's Hospital, Boston, USA; ${ }^{9}$ Department of Research, Innlandet Hospital Trust, Brumunddal, Norway
\end{abstract}

\subsection{6/annrheumdis-2018-EWRR2018.74}

Introduction Rheumatoid Arthritis (RA) patients have increased cardiovascular risk (CV) due to accelerated atherosclerosis (ATS), which significantly contributes to excess mortality in RA. ${ }^{1}$ The increased CV risk cannot be fully explained by traditional risk factors and systemic chronic inflammation appears to play a crucial role. Interestingly, IL-7, a proinflammatory cytokine involved in RA pathogenesis, appears to play a role also in $\mathrm{ATS}^{2}$ but its effect on cardiovascular disease (CVD) in RA has not been studied yet.

Objectives To examine serum IL-7 levels and expression of IL7, IL-7R, CD3 and CD20 in aortic adventitia of RA and nonRA patients with coronary artery disease (CAD) and to search for relationships between systemic IL-7 levels and expression of vascular markers, cardiovascular risk factors including metabolic and inflammatory parameters.

Methods We examined 19 RA and 20 non-RA patients undergoing coronary artery bypass graft surgery included in the Feiring Heart Biopsy Study. Serum IL-7 levels were measured by chemiluminescence (MSD). Biopsies from the adventitia of thoracic aorta from a subset of patients (12 RA and 14 nonRA) were stained for IL-7, IL-7R, CD3 and CD20 by immunohistochemistry and scored per $\mathrm{mm}^{2}$ of tissue.

Results Non-RA patients had lower IL-7 serum levels than RA $(3.4 \pm 3.3$ vs. $6.7 \pm 3.5, p<0.05)$. Independently of RA diagnosis, IL-7 significantly correlated with CRP (rho $=0.450$, $\mathrm{p}=0.008)$, triglycerides $(\mathrm{TG}, \mathrm{rho}=0.566, \mathrm{p}=0.005)$, glucose $(r h o=0.642, p=0.001)$ and hypertension $(p=0.036)$. Levels of IL-7 were associated with New York Heart Association class (rho=0.429, $\mathrm{p}=0.014)$ and this was stronger in non-RA patients $(\mathrm{rho}=0.577, \mathrm{p}=0.010)$. No associations were found with smoking or markers of CVD severity (i.e., numbers of arteries with stenosis or previous myocardial infarcts (MI)). The number of IL-7 +and IL-7R+cells $/ \mathrm{mm}^{2}$ in adventitia were significantly higher in RA $(134.2 \pm 45.5$ and 144 \pm 49.9 respectively) than non-RA patients $(46.9 \pm 22.8$ and $54.4 \pm 20.2, p<0.005)$ and were associated with serum IL-7 levels $(\mathrm{rho}=0.551$ and $\mathrm{rho}=0.588, \mathrm{p}<0.01)$. Both IL-7 +and IL7R + cells were associated with a positive history of MI $(p=0.047$ and $p=0.005)$ and IL-7R+cells with the number of previous MIs ( $r h o=0.408, p=0.038$ ). Only in RA patients, IL$7 \mathrm{R}+$ cells showed a trend for correlation with $\mathrm{TG}$ $(\mathrm{rho}=0.771, \mathrm{p}=0.072)$. IL-7 + and IL-7R+cells correlated with CD3 (rho $=0.688, \mathrm{p}=0.013$ and $\mathrm{rho}=0.630, \mathrm{p}=0.028$ ), but no correlation was found with CD20. Cholesterol and HDL levels were associated with IL-7 +cells only in non-RA patients (rho=0.729, p=0.04 and rho=0.733, p=0.038).

Conclusions Among patients with CAD, those with RA had higher serum IL-7 and a greater expression of both IL-7 and IL-7R is aortic adventitia. Systemic levels of IL-7 were related to its vascular expression. Thus, the IL-7/IL-7R axis may play a role in the accelerated ATS observed in RA; further studies are needed to elucidate the precise role of IL-7 in CV risk in RA.

\section{REFERENCES}

1. Kaplan MJ. Curr. Opin. Rheumatol 2006;18(3):289-297.

2. Damås JK, et al. Circulation 2003;107(21):2670-2676.

Acknowledgements None.

Disclosure of interest None declared

\section{P056 IMPORTANT ROLE OF CD11C+ DENDRITIC CELLS IN INFLAMMATORY ARTHRITIS}

${ }^{1} \mathrm{~A}$ Puchner, ${ }^{1} \mathrm{~V}$ Saferding, ${ }^{2} \mathrm{R}$ Pfeifle, ${ }^{2} \mathrm{G}$ Krönke, ${ }^{1} \mathrm{~K}$ Redlich, ${ }^{1} \mathrm{~J}$ Smolen, ${ }^{1} \mathrm{~S}$ Blüml* ${ }^{1}$ Medizinische Universität Wien, Wien, Austria; ${ }^{2}$ University Hospital Erlangen, Erlangen, Germany

\subsection{6/annrheumdis-2018-EWRR2018.75}

Introduction The main function of dendritic cells (DCs) is to present antigen to T-cells and therefore they play an important role in bridging the innate and the adaptive immune response. However, DCs can be divided in different subsets, which have intrinsic differences that lead to functional specialisation in the generation and maintenance of autoimmunity. Therefore the aim of our study was to investigate the role of CD $11 \mathrm{c}^{+}$conventional DCs and monocytes dervived DCs in inflammatory arthritis.

Methods We analysed histological sections of $\mathrm{K} / \mathrm{BxN}$ serum transfer arthritis as well as hTNFtg arthritis for the presence of $\mathrm{CD} 11 \mathrm{c}^{+}$cells by immunohistochemistry. We also performed synovial biopsies and analysed the cellular composition of the inflammatory infiltrate with respect to DCs. We used CD11cdiphteria toxin receptor (DTR) transgenic mice, which express the human diphtheria-toxin receptor under the CD11c promoter, allowing for specific depletion of $\mathrm{CD}_{11 \mathrm{c}^{+}}$cells by administration of diphtheria toxin (DT). $\mathrm{K} / \mathrm{BxN}$ serum transfer arthritis was induced, and mice were given either DT or PBS or in wt and BARF3 deficient mice. In addition CD11c DTR mice were crossed into hTNFtg animals and also received either DT or PBS. The severity of arthritis was determined clinically and histologically.

Results We show that $\mathrm{Cd} 11 \mathrm{c}^{+}$cells are present in significant numbers in the synovia of $\mathrm{K} / \mathrm{BxN}$ and TNF driven arthritis. Both $\mathrm{CD}^{+} \mathrm{CD} 11 \mathrm{c}^{+}$and $\mathrm{CD} 11 \mathrm{~b}^{+} \mathrm{CD} 11 \mathrm{c}^{+}$, can be found in synovial tissue. In $\mathrm{K} / \mathrm{BxN}$ serum transfer arthritis, clinical scores showed that CD11c-DTR transgenic mice that received DT had significantly reduced paw swelling and loss of grip strength compared to PBS treated animals. Histological analysis found reduced inflammation after the depletion of $\mathrm{CD} 11 \mathrm{c}^{+}$cells in $\mathrm{K} / \mathrm{BxN}$ arthritis. In addition local bone destruction and the number of osteoclasts was significantly reduced. Analysis of $\mathrm{K} / \mathrm{BxN}$ arthritis in wt mice and $\mathrm{BATF} 3^{-/}$ mice, which lack $\mathrm{CD} 8^{+} \mathrm{CD} 11^{+}$DCs revealed no difference in arthritis severity between the two groups. In addition to $\mathrm{K} /$ $\mathrm{BxN}$ arthritis, we found that also in TNF-driven arthritis 
depletion of $\mathrm{CD}_{11 \mathrm{c}^{+}}$cells led to a significant reduction of synovial inflammation and a complete depletion of osteoclasts. Conclusions These data show that in addition to initiating an adaptive immune response, $\mathrm{CD} 11 \mathrm{c}^{+}$dendritic cells, are also involved in innate effector mechanisms of inflammatory arthritis. Especially $\mathrm{CD} 11 \mathrm{~b}^{+} \mathrm{CD} 11 \mathrm{c}^{+}$and monocyte derived inflammatory seem to play a role in inflammatory arthritis, suggesting that they could be an important therapeutic target for patients suffering from inflammatory arthritis.

Disclosure of interest None declared

\section{P057 EFFECTS OF ANTI-TNF THERAPY ON VASCULAR BIOMARKER LEVELS IN RHEUMATOID ARTHRITIS}

'A Hamar*, 'E Végh, 'Á Horváth, 'S Szántó, '⿳G Szucs, 'A Pusztai, 'A Domján, ${ }^{2} \mathrm{~K}$ Hodosi, ${ }^{2} \mathrm{G}$ Kerekes, ${ }^{3} \mathrm{R}$ Gesztelyi, ${ }^{4}$ J Zsuga, ${ }^{5} \mathrm{Z}$ Prohászka, ${ }^{1} \mathrm{Z}$ Szekanecz. ${ }^{1}$ Department of Medicine, Division of Rheumatology; ${ }^{2}$ Department of Medicine; ${ }^{3}$ Department of Pharmacology and Pharmacotherapy; ${ }^{4}$ Department of Health Systems Management and Quality Management for Health Care, University of Debrecen, Debrecen; ${ }^{5}$ Third Department of Internal Medicine, Semmelweis University, Budapest, Hungary

\subsection{6/annrheumdis-2018-EWRR2018.76}

Introduction Prevoius studies have shown an increased risk of cardiovascular disease in rheumatoid arthritis (RA), due to RAassociated inflammation. Different vascular biomarkers, such as anti-hsp65 antibodies, asymmetric dimethylarginine (ADMA) and B-type natriuretic peptide (BNP) have been associated with atherosclerosis and RA. Anti-hsp65 antibodies were found in RA patients and these antibodies linked also to inflammation and atherosclerosis. ADMA is an endogenous competitive inhibitor of NOS and consequential can lead to increased nitrosative and oxidative stress. ADMA has been implicated with atherosclerosis, and also with rheumatoid arthritis. BNP also associated to cardiovascular diseases.

Objectives The aim of this study was to assess the effects of anti-TNF therapy on different vascular biomarkers, such as anti-hsp65, ADMA and BNP in patients with RA and their correlation with different laboratory and clinical markers.

Methods Altogether 36 RA patients were recruited and treated with either etanercept (ETN) or certolizumab pegol (CZP) in this 12 months follow-up study. Assessments were performed at baseline, at month 6 and 12. Amounts of IgG antibodies reacting with recombinant $\mathrm{M}$. bovis hsp65 (Lionex, Braunschweig, Germany) were measured by ELISA. ADMA was assesed by HPLC with fluorescent detection. BNP fragments were assessed by commercially avaiable ELISA kit (Biomedica, Vienna). In addition, disease activity (DAS28), age, disease duration, CRP, IgM rheumatoid factor (RF), anti-CCP (aCCP) and plasma lipid levels were also measured. Arterial flowmediated vasodilation (FMD), carotid intima-media thickness (cIMT) and arterial pulse-wave velocity (PWV) were assessed by ultrasound.

Results There were no significant changes in the levels of antihsp60, ADMA and BNP due to anti-TNF therapy. However, baseline level of BNP is correlated with the levels of RF $(\mathrm{R}=0.479, \mathrm{p}=0.004)$ and $\mathrm{aCCP}(\mathrm{R}=0.591, \mathrm{p}<0.001)$. Serum BNP levels at baseline and at month 6 were significantly increased in RF positive compared to RF negative patients $(680.60 \pm 381.64$ versus $292.94 \pm 198.27 \mathrm{pmol} / \mathrm{L} ; \mathrm{p}=0.007$ and $668.95 \pm 346.51$ versus $312.20 \pm 207.01 \mathrm{pmol} / \mathrm{L} ; \mathrm{p}=0.001)$ and also in aCCP postive compared to aCCP negative patients $(670.61 \pm 323.04$ versus $137.98 \pm 436.41 \mathrm{pmol} / \mathrm{L} ; \mathrm{p}=0.030$ and $652.93 \pm 283.21$ versus $\quad 456.48 \pm 423.11 \mathrm{pmol} / \mathrm{L} ; \quad \mathrm{p}=0.021)$.
Furthermore we found the following correlations between baseline values: anti-hsp60 level correlated with ADMA $(\mathrm{R}=0.900, \mathrm{p}=0.037)$, triglyceride $(\mathrm{TG}) \quad(\mathrm{R}=0.462, \mathrm{p}=0.040)$ and PWV $(\mathrm{R}=0.564, \mathrm{p}=0.040)$. Baseline level of ADMA positively correlated with body mass index $(B M I)$ score $(R=0.720$, $\mathrm{p}=0.040$ ) and also with HDL levels (high density lipoprotein) of patients $(\mathrm{R}=0.473, \mathrm{p}=0.047)$.

Conclusions BNP levels were significantly higher in $\mathrm{RF}+$ compared to RF- patients, which imply that BNP may associate with RF positivity. Specific biomarkers, such as ADMA, anti-hsp60 and BNP may play important role cardiovascular disease in RA.

Acknowledgements The work is supported by the GINOP2.3.2-15-2016-00015/I-KOM TEAMING project.

Disclosure of interest None declared

\section{\begin{tabular}{|l|l}
\hline P058 S100 PROTEINS EFFECTIVELY DISCRIMINATE SYSTEMIC \\
\hline
\end{tabular} LUPUS ERYTHEMATOSUS PATIENTS FROM HEALTHY CONTROLS, BUT ARE NOT ASSOCIATED WITH MEASURES OF DISEASE ACTIVITY}

1,2B Šumová* ${ }^{1,2}$ J Závada, ${ }^{2}$ LA Cerezo, ${ }^{3} \mathrm{M}$ Uher, ${ }^{2} \mathrm{H}$ Hulejová, ${ }^{4} \mathrm{M}$ Grigorian, ${ }^{1,2} \mathrm{~K}$ Pavelka, 1,2J Vencovský, 1,2 L Šenolt. 'Department of Rheumatology, 1st Faculty of Medicine, Charles University, Prague, Czech Republic; ${ }^{2}$ Institute of Rheumatology, Prague, Czech Republic, Prague; ${ }^{3}$ Institute of Biostatistics and Analyses, Masaryk University, Brno, Czech Republic; ${ }^{4}$ Department of Neuroscience, University of Copenhagen, Copenhagen, Denmark

\subsection{6/annrheumdis-2018-EWRR2018.77}

Introduction The S100 proteins are important regulators of diverse calcium-dependent cellular processes including growth regulation, migration and apoptosis. Dysregulated expression of multiple members of S100 family is a common feature of cancer and several autoimmune diseases.

Objectives The aim of this study was to examine whether circulating levels of S100A4, S100A8/9 and S100A12 proteins could be useful as diagnostic or activity specific markers in systemic lupus erythematosus (SLE).

Methods S100 plasma levels were measured by ELISA in a cohort study of 44 patients with SLE, 8 patients with incomplete SLE (iSLE) and 43 healthy controls (HCs). Disease activity was assessed using SLEDAI-2 K. We examined cross sectional associations between concentrations of S100 proteins and SLE status, SLEDAI-2 K scores, and levels of conventional biomarkers.

Results Plasma levels of all analysed S100 proteins (S100A4, S100A8/9 and S100A12) were significantly higher in SLE patients compared to HCs $(\mathrm{p}<0.001, \mathrm{p}<0.01, \mathrm{p}<0.001$, respectively). In iSLE patients, the levels of S100A4 and S100A12 but not S100A8/9 were significantly higher compared to HCs $(\mathrm{p}<0.001, \mathrm{p}<0.05, \mathrm{p}=\mathrm{ns}$, respectively). ROC curve analysis was performed to establish the optimal threshold to discriminate SLE patients from HCs based on S100 levels. At the optimal cutoff point of $238 \mathrm{ng} / \mathrm{ml}$, the area under curve (AUC) for S100A4 was 0-990 $(95 \%$ CI: 0.977 to $1.000, \mathrm{p}<0.001)$ with a sensitivity of $96 \%$ and specify of 93.0\%. The remaining two proteins also showed significant, but not as strong discriminative value [S100A8/9: AUC 0.684 (95\% CI: 0.572 to $0.795, \mathrm{p}<0.05)$; S100A12: AUC 0.809 (95\% CI: 0.719 to $0.898, \mathrm{p}<0.001]$. We found that only S100A12 levels were significantly associated with the SLEDAI$2 \mathrm{~K}$ score $(\mathrm{r}=0.318, \mathrm{p}=0.035)$. Both $\mathrm{S} 100 \mathrm{~A} 8 / 9$ and $\mathrm{S} 100 \mathrm{~A} 12$ levels were significantly higher in SLE patients with arthritis $(\mathrm{p}=0.043, \mathrm{p}=0.015$, respectively) and with haematological 